\title{
An uncommon mecha- nism of brachial plexus injury. A case report
}

Divya Bhardwaj FFARCSI, Philip Peng FRCPC

Purpose: To report a case of brachial plexus injury occurring on the contralateral side in a patient undergoing surgery for acoustic neuroma through translabrynthine approach.

Clinical Features: A 5|-yr-old woman underwent surgery for acoustic neuroma through translabrynthine approach in the left retroauricular area. She had a short neck with a BMI of 32. Under anesthesia, she was placed in supine position with Sugita pins for head fixation. The head was turned $45^{\circ}$ to the right side and the neck was slightly flexed for access to the left retroauricular area, with both arms tucked by the side of the body. Postoperatively, she developed weakness in the right upper extremity comparable with palsy of the upper trunk of the brachial plexus. Hematoma at the right internal jugular vein cannulation site was ruled out by CAT scan and MRI. The only remarkable finding was considerable swelling of the right sternocleidomastoid and scalene muscle group, with some retropharyngeal edema. An EMG confirmed neuropraxia of the upper trunk of brachial plexus. She made a complete recovery of sensory and motor power in the affected limb over the next three months with conservative treatment and physiotherapy.

Conclusions: Brachial plexus injury is still seen during anesthesia despite the awareness about its etiology. Malpositioning of the neck during prolonged surgery could lead to compression of scalene muscles and venous drainage impedance. The resultant swelling in the structures surrounding the brachial plexus may result in a severe compression.

Objectif : Citer le cas d'une atteinte controlatérale du plexus brachial qui s'est produite chez une patiente subissant l'ablation d'un névrome acoustique par voie translabyrinthique.

Eléments cliniques : Une femme de 51 ans a subi l'ablation d'un névrome acoustique rétro-auriculaire gauche par voie translabyrinthique. Elle avait un cou court et un IMC de 32. Sous anesthésie, on l'a placée en en décubitus dorsal et on a fixé sa tête à l'aide de broches de Sugita. Sa tête était tournée vers la droite, de $45^{\circ}$ et son cou légèrement fléchi pour permettre un accès facile à la zone rétro-auriculaire gauche tandis que les deux bras étaient collés au corps de chaque côté. Après l'intervention, une faiblesse comparable à une paralysie du premier tronc primaire du plexus brachial s'est développée au membre supérieur droit. La possibilité d'un hématome au site de la canule de la veine jugulaire interne a été écartée à l'examen tomodensitométrique et à l'IRM. La seule constatation notable était un important gonflement du groupe musculaire sterno-cléido-mastoïdien et scalène droit et un certain oedème rétropharyngien. Un EMG a confirmé une paralysie du premier tronc primaire du plexus brachial. Pendant les trois mois qui ont suivi, la récupération motrice et sensitive a été complète dans le membre atteint grâce à un traitement conservateur et à la physiothérapie.

Conclusion : L'atteinte du plexus brachial est toujours possible pendant l'anesthésie même si on a à l'esprit son l'étiologie. Un mauvais positionnement du cou pendant une chirurgie prolongée peut provoquer la compression des muscles scalènes et accroître l'impédance du drainage veineux, la résultante étant un gonflement des structures autour du plexus brachial pouvant causer une sévère compression.

From the Department of Anaesthesia, The Toronto Hospital, Western Division, University of Toronto, 399 Bathurst Street, Toronto, Ontario M5T 258.

Address correspondence to: Dr. Philip Peng. Phone: 416-603-5118; Fax: 416-603-6494; E-mail: ppeng@torhosp.toronto.on.ca Accepted for publication November 22, 1998 
B RACHIAL plexus injury is one of the most common nerve injuries during anesthesia ${ }^{1,2}$ and is a common reason for malpractice claims. ${ }^{3}$ Anesthesiologists are particular careful to avoid malposition intraoperatively to prevent neurological injuries. Despite this, such injuries occur. This case report describes an unusual cause of brachial plexus injury that may be related to malpositioning.

\section{Case Report}

A 51-yr-old woman underwent surgery for excision of an acoustic neuroma through a translabrynthine approach on the left side. Her past history was unremarkable except for hypothyroidism which was well controlled. She had no pre-existing neurological disorder. Her height was $155 \mathrm{~cm}$ and weight $73 \mathrm{~kg}$ (BMI 32 ). Anesthesia was induced in the usual manner with midazolam, fentanyl, thiopental and succinylcholine. Invasive monitoring included right radial arterial line and right internal jugular venous cannulation (IJV). On the first attempt at central venous cannulation, the needle went into the vein easily but the guide wire could not be threaded. On the second attempt, the vein was cannulated easily.

The patient was then placed in supine position with Sugita pins for head fixation. The head was turned $45^{\circ}$ to the right side and the neck was slightly flexed for access to the left retroauricular area, with both arms tucked by the side of the body. The shoulders were neither pulled downward nor elevated with roll for exposure. It was somewhat difficult to position her satisfactorily as she had a short neck and the chin tended to press against the shoulder. Finally, she was positioned with reasonable exposure to the retroauricular area and the space between the chin and the shoulder was approximately one finger-breadth.

Anesthesia was maintained on $\mathrm{N}_{2} \mathrm{O} / \mathrm{O}_{2}$, isoflurane, doxacurium and fentanyl. Surgery was uneventful and there were no prolonged hypotensive episodes. The duration of surgery was $12 \mathrm{hr}$ and the core temperature of patient was kept $>34 \mathrm{C}$ throughout surgery. The patient was transferred to the ICU after surgery and, later that night, the trachea was extubated.

The next morning, the patient complained of weakness in the right arm and left sided facial numbness. On examination, there was swelling and induration in the right side of the neck extending from the submandibular to infra-clavicular area measuring $17.5 \mathrm{~cm}$ in diameter. Facial swelling including the eye lids and lips was also noted. Furthermore, there were findings compatible with seventh, eighth and partial fifth cranial nerve deficits on the left side. In addition, pin prick sensation was decreased on the radial side of right arm and forearm. Motor examination of right upper extremity revealed minimal shoulder flexion, no elbow flexion, good grip strength but unable to lift hand against gravity. The motor power was triceps 4 , rhomboids 4 , supraspinatus 0 , infraspinatus 0 , deltoid 0 , biceps 0 and wrist and fingers flexor/extensor 5. Deep tendon reflexes were absent for the right biceps and brachioradialis muscles. A diagnosis of right sided brachial plexus palsy of unknown etiology involving mainly the upper trunk was made. The left sided cranial nerve lesions were thought to be surgery related. ${ }^{4}$

Neurology and ENT specialists were consulted. A CAT scan was performed which showed no obvious hematoma in the neck at the IJV cannulation site. However, the entire right sternocleidomastoid and scalene muscles were edematous together with extensive soft tissue swelling in the anterior triangle and some retropharyngeal swelling. The swelling was not severe enough to cause airway compromise. An MRI revealed the same findings. No cervical disc herniation was seen.

The patient was treated conservatively with physiotherapy, galvanic stimulation and support to the affected limb. She developed neuropathic pain about one week later in the affected extremity which was treated with demerol, NSAIDs and amitryptilline. Over the next few days there was some improvement in sensory and motor power. An EMG performed a week postoperatively revealed changes consistent with neuropraxia involving upper trunk of the right brachial plexus. The treatment was continued and the patient was discharged two weeks after surgery. By then she had made a partial recovery from the brachial plexus injury. At follow-up three months after discharge, she had made a complete recovery in the affected limb.

\section{Discussion}

The brachial plexus is vulnerable to injury during anesthesia and surgery because of lack of mobility of the brachial plexus. ${ }^{1,5,6}$ It is firmly attached proximally to the vertebre and prevertebral fascia and distally to the axillary sheath. Therefore, stretching of this plexus can cause injury because of its relative immobility. Furthermore, any compression from surrounding structures can cause ischemia in the nerve trunks. An anesthetized patient is unable to respond to the pain, numbness or weakness as a result of stretch or compression and is therefore at risk of serious injury. Other factors like hypovolemia, hypothermia, diabetes, coagulopathy and induced hypotension all increase the risk of nerve injury. ${ }^{6}$

Hematoma at the site of the IJV was ruled out by CT scan and MRI. The proximity of the hematoma 
and upper trunk of the brachial plexus in the posterior triangle can cause such an injury. ${ }^{7-9}$ Other nerve injuries have been sporadically reported with IJV cannulation. ${ }^{10-14}$ Needle trauma ${ }^{8}$ was unlikely since the injury involved the whole upper trunk and would unlikely be achieved by two uneventful attempts. Furthermore, the EMG finding at one week suggested neuropraxia involving the whole upper trunk. Cervical disc prolapse was ruled out by MRI. There was no stretching involved as the neck was turned towards the side of injury and there was no abduction at the shoulder joint. ${ }^{13}$

Idiopathic brachial neuritis (IBN) is a well recognized clinical syndrome. ${ }^{15}$ It is characterized by patchy weakness and atrophy of muscles of the shoulder girdle. The weakness is often preceded by intense and unbearable pain, maximum in intensity at the onset of symptoms. ${ }^{16}$ The etiology is unknown but a strong link to an immune reactive phenomenon has been suggested. ${ }^{17}$ It may be confused with brachial stretch injuries related to positioning as the former can also occur in the postoperative period. In our patient, the neurological involvement was rather extensive instead of patchy. Pain was neither the presenting nor predominant symptom. All these features suggest against the diagnosis of IBN.

The most likely cause in our case report was thought to be excessive rotation in a patient with a short neck for a prolonged period. In turning the head to the right, the proximal attachments of the right scalene muscles were displaced posteriorly, making the scalene muscles taut and thus narrowing the interscalene groove. Suboptimal positioning of the neck with the chin in close proximity to the shoulder resulted in compression of the muscles and poor venous drainage on the right side of the neck. With time, this could result in muscle ischemia and swelling, leading to severe entrapment of the brachial plexus in the interscalene groove. This case highlights again the importance of positioning in a patient with short neck for prolonged surgery.

\section{References}

1 Cooper DE, Jenkins RS, Bready L, Rockwood CA Jr. The prevention of injuries of the brachial plexus secondary to malposition of the patient during surgery. Clin Orthop 1988; 228: 33-41.

2 Dawson DM, Krarup C. Perioperative nerve lesions. Arch Neurol 1989; 46: 1355-60.

3 Kroll DA, Caplan RA, Posner K, Ward RJ, Cheney FW. Nerve injury associated with anesthesia. Anesthesiology 1990; 73: 202-7.
4 Wiet $R J$, Teixido M, Liang J-G. Complications in acoustic neuroma surgery. Otolaryngol Clin North Am 1992; 25: 389-412.

5 Parks BJ. Postoperative peripheral neuropathies. Surgery 1973; 74: 348-57.

6 Berwick JE, Lessin $M E$. Brachial plexus injury occuring during oral and maxillofacial surgery. J Oral Maxillofac Surg 1989; 47: 643-5.

7 Paschall $R M$, Mandel S. Brachial plexus injury from percutaneous cannulation of the internal jugular vein (Letter). Ann Emerg Med 1983; 12: 58-60.

8 Frasquet FJ, Belda FJ. Permanent paralysis of C-5 after cannulation of the internal jugular vein (Letter). Anesthesiology 1981; 54: 528.

9 Sylvestre DL, Sandson TA, Nachmanoff DB. Transient brachial plexopathy as a complication of internal jugular vein cannulation. Neurology 1991; 41: 760.

10 Hoffman JC. Permanent paralysis of the accessory nerve after cannulation of the internal jugular vein (Letter). Anesthesiology 1983; 58: 583-4.

11 Vest $J V$, Pereira $M B$, Senior RM. Phrenic nerve injury associated with venipuncture of the internal jugular vein. Chest 1980; 78: 777-9.

12 Stock MC, Downs JB. Transient phrenic nerve blockade during internal jugular vein cannulation using the anterolateral approach. Anesthesiology 1982; 57 : 230-3.

13 Po BT, Hansen HR. Iatrogenic brachial plexus injury: a survey of literature and of pertinent cases. Anesth Analg 1969; 48: 915-22.

14 Parikh RK. Horner's syndrome. A complication of percutaneous catheterisation of internal jugular vein. Anaesthesia 1972; 27: 327-9.

15 Malamut RI, Marques W, England JD, Sumner AJ. Postsurgical idiopathic brachial neuritis. Muscle Nerve 1994; 17: 320-4.

16 Dillin L, Hoaglund FT, Scheck M. Brachial neuritis. J Bone Joint Surg 1985; 67: 878-9.

17 Fibuch EE, Mertz J, Geller B. Postoperative onset of idiopathic brachial neuritis. Anesthesiology 1996; 84: 455-8. 